E N S A I 


\section{A OBRA DRAMÁTICA DE GONÇALVES DIAS}

Ana Cláudia Rôla Santos*

RESUMO :

Este artigo consiste na leitura das peças teatrais de Gonçalves Dias, inserindo-as no panorama teatral brasileiro do século XIX.

PALAVRAS-CHAVE: literatura, história, teatro brasileiro.

Ao pesquisarmos a história do teatro brasileiro, deparamo-nos com afirmações que questionam a existência de um teatro nacional antes do século XX. Tais afirmações estão calcadas em comparações entre o Brasil e algumas nações européias, e na visão do teatro como arte independente da literatura que se realiza apenas no palco, e como encenação. Porém, o gênero dramático, como o lírico e o épico, foi, até o século XIX, considerado uma das partes constituintes da literatura e, o valor do texto literário, um critério adotado para o julgamento de peças teatrais. Desta forma, a existência da literatura dramática brasileira desse período vem comprovar uma grande produção teatral, que não pode ser ignorada.

Relembramos dois momentos relevantes do teatro no Brasil: no século XVI, o teatro jesuíta, que deve ser tomado como um marco do teatro brasileiro, e, no século XIX, principalmente no período em que floresceu o Romantismo, como um dos gêneros preferidos dos escritores românticos. Para eles, "escrever romances era facultativo. Escrever peças, praticamente obrigatório. Nem historiadores como Varnhagen e Joaquim Norberto, escaparam à regra" (Prado, 1996: 188).

José de Anchieta (1534-1597), que se tornou conhecido como o pioneiro do gênero dramático no Brasil, foi quem compôs e representou nossos primeiros autos e, apesar do objetivo exclusivo de catequização do gentio, não se pode desmerecer o seu

\footnotetext{
* Mestre em Letras: Literatura, História e Memória Cultural (Área de concentração: Literatura Brasileira), 2004.
} 


\section{EMTESE}

Belo Horizonte, v. 9, p. I-28I, dez. 2005

feito. Devido às circunstâncias, as representações jesuíticas distanciaram-se do modelo europeu de teatro da época. Utilizavam a língua tupi e, em muitas peças, o conteúdo baseava-se sempre na dialética bem $x$ mal, representados por "anjos e demônios (encarnados, estes últimos, em chefes indígenas adversários dos jesuítas nas lutas locais contra os huguenotes franceses), além de figuras alegóricas, como Temor e Amor de Deus" (Magaldi, 1999: 4).

No início do século XIX, quando o Brasil torna-se residência da família real portuguesa e precisa assemelhar-se, o mais rápido possível, aos países da Europa, o Príncipe Regente, D. João VI, decreta que se construa no Rio de Janeiro o primeiro "teatro decente e proporcionado à população e ao maior grau de elevação à grandeza em que se acha pela minha residência nela" (Prado, 1999: 26). 0 referido teatro fica pronto em 1813 e, posteriormente, é denominado Teatro João Caetano.

Com o advento do Romantismo, surge a primeira tragédia, Antônio José ou o Poeta da Inquisição, de autoria de Gonçalves de Magalhães (18111882), em 1839, e a primeira comédia, O Juiz de Paz da Roça, de Martins Pena (1815-1847). Ambas serão representadas por João Caetano dos Santos (18081863), considerado, posteriormente, um dos maiores atores do país. Apesar do desejo dos nossos escritores de produzir um teatro "autenticamente" nacional, eles não conseguiam desvencilhar-se das influências européias, principalmente das experiências cênicas francesas, que se impunham como grandes modelos. As peças sobre assuntos estritamente nacionais eram raras, mesmo a de Gonçalves de Magalhães, que no Prefácio declara o seguinte: "esta é, se me não engano, a primeira Tragédia escrita por um Brasileiro e única de assunto nacional". (Prado, 1999: 42) 0 protagonista, Antônio José da Silva (1705-1739), é nascido no Rio de Janeiro, mas parte para Portugal ainda menino e lá obtém toda sua formação social.

No gênero cômico, relevando-se as vărias limitações, Martins Pena ocupa um lugar de destaque pois, sua comédia

(...) representa de fato o marco inicial da fixação dos costumes brasileiros, que são explorados por Joaquim Manoel de Macedo, José de Alencar, França Junior e Artur de Azevedo, os principais cultores do gênero, numa continuidade de trabalhos que vem até o princípio deste século. (Magaldi, 1999: 61). 
Em meados do século XIX, surge também o drama histórico nacional. Com o intuito de contribuir para a formação da nação, os escritores que se aventuraram nesta modalidade pretendiam um conteúdo nacional, nos moldes do romantismo social, mas muitas vezes extrapolavam a imaginação, preterindo a realidade dos fatos, e buscando apresentar, de alguma forma, o Brasil como país independente. Apesar do esforço dos autores, parecia faltar o elemento principal para que o drama histórico pudesse se desenvolver: um fato histórico que fosse memorável e fornecesse subsídios para os escritores levá-10 aos palcos. Nesta época, o único episódio relevante era a Independência, mesmo assim, D. Pedro I deixou de ser considerado herói nacional ao abdicar e, sob a perspectiva histórica, era quase impossível abordar tal episódio por se tratar de um acontecimento muito recente.

Os primeiros dramas históricos nacionais foram A Fidelidade Paulistana, de 1842, e Amador Bueno, de 1847, escritos respectivamente por Joaquim Norberto de Sousa e Silva e Francisco Varnhagen. Coincidentemente, os dois historiadores inspiraramse no mesmo fato, de veracidade e intenção nacionalista discutíveis, que foi a recusa de Amadeu Bueno da Ribeira ao título de rei, oferecido pela população da cidade de São Paulo, em 1642, época da secessão de Portugal da Espanha.

A historiografia teatral destaca, como principais representantes dos dramas históricos nacionais, Calabar, de Agrário de Menezes (1834-1863), O Jesuíta, de José de Alencar (1829-1877), Sangue Limpo, de Paulo Eiró (1836-1871), e Gonzaga ou a Revolução de Minas, de Antônio de Castro Alves (1847-1871). Apesar de não haver provas da influência de uma sobre a outra, todas pretendem apresentar o Brasil como nação nascente e têm o fato da Independência como pano de fundo.

Neste panorama emerge, a obra teatral de Antônio Gonçalves Dias (1823 1864), que não lembra em nenhum aspecto a poesia indianista de traços marcadamente brasileiros, pela qual o autor destaca-se. Gonçalves Dias escreveu quatro dramas: Patkull e Beatriz Cenci, em 1843, quando tinha aproximadamente vinte anos de idade e morava em Lisboa; Leonor de Mendonça, em 1846; e Boabdil, em 1850, no Rio de Janeiro ${ }^{1}$. Os títulos dessas obras remetem-nos a personagens da história universal, o que de certa forma propiciava autenticidade e veracidade ao espetáculo, mas a história, em si, serve apenas para abordar o sentimento amoroso, como a maior 


\section{EMTESE}

Belo Horizonte, v. 9, p. I-28I, dez. 2005

justificativa da existência humana, responsável por toda ação nas referidas peças. As personagens são apresentadas e compreendidas sob o prisma moral e psicológico. 0 desfecho dos fatos é proveniente de uma "hesitação, entre o determinismo moderno e a antiga fatalidade grega, o fatum latino - fado português indiferente ou mesmo hostil a certas pessoas, a certas famílias, marcadas para a desgraça" (Prado, 1996: 91), sem atribuir poder à Providência Divina.

Vejamos rapidamente cada uma delas.

A peça Patkull situa-se no ano de 1707, estende-se de Mecklenburgo a Dresde, e vai até Casimir na Polônia. Patkull, o herói, é um guerreiro destemido, nativo da Livônia, local dominado, sucessivamente, por Carlos XII, da Suécia, por Pedro, o Grande, da Rússia, e por Augusto II, eleito rei da Polônia e posteriormente destronado. Em defesa de sua terra, Patku1l vai para os campos de batalha deixando a noiva, Namry Romhor. 0 anti-herói, Paikel, suposto amigo de Patku11, e antigo namorado de Namry Romhor, com a ausência do guerreiro tenta recuperar o amor da heroína. Embora Namry mantenha o compromisso de honra com Patkul1, Paikel faz com que pareça que Namry traiu o noivo, desencadeando uma série de acontecimentos que culmina com a morte do herói.

A peça Beatriz Cenci passa-se na Itália de 1598 , e retrata um intrigante episódio histórico: a atração de Francisco Cenci por sua filha Beatriz. A protagonista, Beatriz, a princípio tinha uma visão de mundo limitada à ótica do pai, pois passou a infância excluída do convívio social, encerrada em um quarto do palácio, e tendo D. Francisco Cenci como seu único elo de ligação com a sociedade. A relação de D. Francisco com Beatriz é de proprietário/mercadoria, criador/criação. E é ele quem decide a vida que a protagonista deve ter, pois, de acordo com seus padrões, foi ele quem a preparou para a vida. D. Francisco "cria" a mulher perfeita dentro das suas concepções: a que confia e respeita e, sobretudo, não distingue amor paternal de amor marital. Cenci tem um plano de sedução tão bem elaborado que em hipótese alguma pode pô-10 a perder. Não deixa que suas intenções transpareçam, cerca Beatriz de armadilhas dissimuladas, desarmando-a totalmente e evitando sempre um suposto contra-ataque. A estratégia do pai parecia perfeita; tem a confiança e a admiração da filha, e apenas espera uma oportunidade para 
"atacar", quando ocorre um imprevisto: Beatriz se apaixona por Márcio, um cavaleiro que a cortejava às escondidas. Mesmo assim, o incesto, consumação da sedução, realiza-se.

No decorrer da peça, é a madrasta de Beatriz, Lucrécia, quem desperta o leitor para as verdadeiras intenções de D. Francisco, e também quem o acusa de estar seduzindo a própria filha. Apesar da aparente posição de igualdade com o marido, D. Lucrécia the é submissa. Obrigada por ele, comparece a um sarau, que não passava de uma cilada para consumar-se o incesto. Francisco Cenci ainda faz com que Beatriz confesse a Márcio, no momento em que este vem pedir-1he a mão em casamento, que não é mais pura e digna dele. Beatriz aproveita a ocasião para mostrar as artimanhas usadas pelo pai para seduzi-1a, as quais só percebeu depois do fato consumado, o que faz com que Márcio tencione vingar-se do velho Cenci em honra de sua amada. Esse episódio é o marco da mudança de postura da protagonista que, a princípio, hesita em vingar-se do pai, mas admite ser este sentimento mais forte do que ela. Lucrécia aproveita-se da sede de vingança de Beatriz e Márcio para exteriorizar o ódio que sente por D. Francisco, e os três tramam o assassinato do Cenci. Beatriz finge ceder aos encantos do pai e coloca, orientada pela madrasta, um sonífero que, na realidade, é um veneno, no vinho, a fim de adormecê-lo para que Márcio possa matá-10. Porém D. Francisco descobre a trama, e manda matar Márcio; sem desconfiar que Lucrécia estivesse envolvida no plano. No final, ela se declara cúmplice, e ele, apesar de moribundo, consegue matá-la.

A peça Boabdil passa-se durante o fim do domínio mouro em Granada, cidade cercada pelos cristãos. Além do conflito entre árabes e cristãos, há a disputa pelo poder entre as famílias Zegis, Gomeles e Abencerrages. Boabdil, último rei mouro de Granada, é casado com Zoraima, que ama Aben-Hamet, um antigo namorado que se torna amigo do rei. 0 enredo é muito parecido com o de Patkull, uma vez que apresenta o amor entre dois jovens, que é interrompido por um acordo feito pelo pai que promete a filha em casamento a um outro homem. Posteriormente, ocorre 0 reaparecimento do antigo namorado na condição de amigo do protagonista, além da coexistência do drama íntimo e do drama político, este apenas como pano de fundo. Boabdill desconfia da infidelidade da esposa e sabe que o responsável pela 


\section{EMTESE}

Belo Horizonte, v. 9, p. I-28I, dez. 2005

traição é um Abencerrage. Manda matar todos os integrantes desta família, poupando, sem saber, o culpado, pois o nome verdadeiro do seu amigo AbenHamet, a quem destina a guarda da esposa, era Ibrahim Abencerrage.

Boabdi11 não desempenha bem a sua função de rei. Nas questões políticas parece não saber, ou não querer defender Granada, preocupando-se mais com as questões amorosas, caracterizadas pelo ódio e pela vingança, que substituíram o amor que sentira antes por Zoraima. 0 amor de Aben-Hamet e Zoraíma é o grande responsável pela traição da confiança que Boabdill depositou no casal, pois ambos lutam com todas as suas forças contra este sentimento, mas nesta peça parece que o destino subjugou os atos humanos.

Já a peça Leonor de Mendonça ocorre em Portugal, no ano de 1512, e trata de um suposto caso de adultério da Duquesa de Bragança, Leonor de Mendonça. Escrita em 1846, entre Patkull e Boabdill, pode ser considerada uma obra prima dramática não só de Gonçalves Dias mas também do teatro nacional. 0 enredo passa-se em Vila Viçosa, residência campal da nobre família Bragança, local em que ocorreu o assassinato da Duquesa Leonor de Mendonça, acusada de adultério por seu marido, D. Jaime, quarto Duque da Casa de Bragança, sem que fosse provada sua culpa. 0 pivô das suspeitas do Duque é um jovem cavaleiro, Antônio Alcoforado, que nutre um misto de amor e veneração pela Duquesa.

Leonor de Mendonça, além de ser a única peça editada em vida por Gonçalves Dias, destaca-se ainda por um belíssimo Prólogo, em que o autor trata de questões teóricas acerca da estética romântica, e deixa transparecer a maturidade e seu gênio ao não limitá-la ao local e tempo da criação.

Todas as peças de Gonçalves Dias são, portanto, inspiradas em fatos históricos e têm o desenlace sangrento como ponto comum: em Patkul, o herói morre ao ser incitado por Paikel a lutar nas disputas territoriais; em Beatriz Cenci, o vilão Francisco Cenci é envenenado, mas antes de morrer mata Lucrécia, madrasta e confidente de Beatriz; em Leonor de Mendonça, a protagonista é acusada de adultério e, apesar de inocente, é assassinada pelo marido; e, em Boabdil, o amor de Zoraima e Aben-Hamet é descoberto, e o casal condenado à morte. Além disso, as peças apresentam, de alguma forma, personagens femininas sujeitas ao domínio do pai e do marido. Namry Romhor abdica do amor a Paikel em respeito ao pai que a prometeu 
a Patkul1; Beatriz deixa-se seduzir pelo pai; Zoraima casa-se com Boabdill por imposição paterna, e Leonor de Mendonça é castigada pelo marido, por um crime que não cometeu.

Ao analisarmos as peças de Gonçalves Dias sob uma linha cronológica, observamos que as duas primeiras, Patkull e Beatriz Cenci, frutos de um espírito jovem, apresentam alguns problemas na estruturação e no entendimento do enredo. Em Patkull, drama composto por cinco atos, o protagonista desaparece no final do ato I e reaparece em cena nos dois últimos atos, quando já está sendo julgado e condenado à morte. Neste entremeio, o triângulo Patkull - Namry - Paikel é substituído por Namry - Paikel - Berta, esta última, dama de companhia de Namry, que havia sido seduzida e abandonada, por Paikel, no passado. Os três habitam a mesma casa na ausência de Patkull, e vivem se acusando uns aos outros. Desta forma, o leitor não tem acesso a um fato muito importante, de perspectiva politica, que seria o período de ausência de Patkull enquanto lutava em defesa da Livônia. Além de não ter relatado os fatos históricos ocorridos no período, o autor usa, para preencher a lacuna, um segundo triângulo amoroso de baixo valor dramático. Outro problema da peça, que prejudica o entendimento do leitor, é a forma como Gonçalves Dias refere-se a Namry Romhor, ora tratando-a pelo nome e ora pelo sobrenome, como se fosse uma outra personagem.

Em Beatriz Cenci, o enredo, o tema e as personagens são dignos de um drama original e estruturado, mas o autor peca por apresentar tudo muito rápido. 0 incesto é seguido de parricídio e, assim que o crime ocorre, finda-se o drama. 0 texto é produto de uma mente jovem, em que várias idéias coexistem e desencadeiam fatos atropelados, sem refletir sobre o efeito que causará tal exposição de idéias, principalmente por ter colocado, abertamente, a consumação de um incesto, assunto até então tratado de forma indireta.

Com relação aos últimos dramas, Leonor de Mendonça e Boabdill, do primeiro há mais que enaltecer do que depreciar. Gonçalves Dias trabalhou o material do qual dispunha de forma lúcida, conseguiu suprir a falta de domínio cênico, observada nas peças anteriores. Leonor de Mendonça é, sem dúvida, o ponto culminante da carreira dramática deste autor. 


\section{EMTESE}

Belo Horizonte, v. 9, p. I-28I, dez. 2005

Em Boabdill, além de não apresentar nenhum aspecto que mostre a evolução no gênero dramático e/ou um aprimoramento do escritor, retoma problemas observados na sua primeira peça, caracterizados pela inexperiência no exercício desta modalidade literária. Dentre os problemas observados, destacamos, principalmente, a caracterização das famílias Zegris, Gomeles e Abecenrrages, que não são mostradas como grupos, mas a partir de ações individuais. Com relação ao enredo, embora inspirado em um fato histórico, guarda muita semelhança com Patkull e com o gênero folhetinesco, pois o propulsão trágica estrutura-se praticamente no conflito interno de Zoraima que ama, Aben-Hamet, contra seu desejo.

Essa leitura cronológica da produção teatral de Gonçalves Dias não serve apenas para observarmos os defeitos e as qualidades de sua obra, mas, antes, para mostrar o amadurecimento que o autor alcança na peça Leonor de Mendonça.

NOTA

1. Leonor de Mendonça foi a única experiência editorial do poeta, as demais peças foram publicadas apenas em um volume de obras póstumas, por Antônio Henriques Leal, na primeira década do século XX.

ABSTRACT :

This paper consists in a reading of the Gonçalves Dias' plays, inserting them in the brazilian theatrical scene of the $19^{\text {th }}$ century.

KEY WORDS: literature, history, brazilian theatre.

BENTLEY, Eric. A experiência viva do teatro. Rio de Janeiro: Zahar, 1967.

CONSTATT, Oscar. Repertório Crítico da Literatura Teatro - Brasileiro. Trad. Eduardo de Lima Castro. Rio de Janeiro: Presença, 1978. 
DIAS, Gonçalves. Teatro Completo. Rio de Janeiro: Serviço Nacional de Teatro, 1979.

ESSLIN, Martin. Uma anatomia do drama. Rio de Janeiro: Zahar, 1978.

FARIA, João Roberto. O Teatro na Estante. São Paulo: Ateliê Editorial, 1998.

FERGUSSON, Francis. Evolução e sentido do teatro. Trad. Heloisa de Hollanda G. Ferreira. Rio de Janeiro: Zahar, 1964.

GASSNER, J. Mestres do Teatro. São Paulo: Perspectiva, 1974 .

HUGO, Victor. Do grotesco e do sublime. São Paulo: Perspectiva, 1988.

LESSING, Gotthold Ephraim. De teatro e literatura. Trad. J. Guinsburg. São Paulo: Herder, 1964.

MAGALDI, Sábato. Panorama do teatro brasileiro. 4 ed. São Paulo: Global, 1999.

- Iniciação ao teatro. São Paulo: Ática, 1986.

MARGOT, Berthold. História mundial do teatro. São Paulo: Perspectiva, 2001.

NEVES, Tânia Brandão Pereira. Martins Penna e a Questão do Teatro Nacional. In: Monografias 1977. Rio de Janeiro: Serviço Nacional do Teatro, 1979.

PRAD0, Décio de Almeida. 0 teatro romântico: a explosão de 1830. In: GUINSBURG, J. (0rg.). O Romantismo. São Paulo: Perspectiva/Secretaria da Cultura Ciência e Tecnologia, 1978.

- A personagem de ficção. In: CÂNDIDO, Antônio et ầ. A Personagem de Ficção. São Paulo: Perspectiva, 2002 .

- João Caetano. São Paulo: Perspectiva, 1972.

. História Concisa do Teatro Brasileiro. 1570-1908. São Paulo: EDUSP, 1999.

- O Drama Romântico Brasileiro. São Paulo: Perspectiva, 1996.

SoUZA, J. Galante. O Teatro no Brasil. Rio de Janeiro: Instituto Nacional do Livro, 1960. 